(3rd ed.) New York: Holt, Rinehart \& Winston, 1968.

Mayzner, M. S. \& Tresselt, M. E. Visual information processing with sequential inputs: A general model for sequential blanking, displacement, and overprinting phenomena. Annals of the New York Academy of Sciences, 1970, 169, 599-618.

Mayzner, M. S., Tresselt, M. E., \& Helfer, M. S. A research strategy for studying certain effects of very fast sequential input rates on the visual system. Psychonomic Monograph Supplements, 1967a, 2(5, Whole No. 21), 73-81.
Mayzner, M. S., Tresselt, M. E., \& Helfer, M. S. A provisional model of visual information processing with sequential inputs. Psychonomic Monograph Supolements, 1967b, 2(7. Whole No. 23), 91-108.

Winer, B. J. Statistical principles in experimental design. New York: McGraw-Hill, 1962.

(Received for publication May 9. 1973.)

\title{
Olfactory thresholds and level of anxiety*
}

\author{
CAROLYN K. ROVEE, SANDRA L. HARRIS \\ and \\ RITA YOPP \\ Douglass College, Rutgers-The State University \\ New Brunswick, N.J. 08903
}

Absolute and difference thresholds of n-octanol were determined for 30 college students scoring at extremes of the Taylor Manifest Anxiety Scale. High-anxious Ss produced significantly higher absolute thresholds and more reversals than low-anxious Ss. In the difference threshold task, high-anxious Ss responded within a

*This research was supported by Grant 07-2268 from the Rutgers University Research Council to the senior author. We Rutgers University Research Council to for assistance in data collection and analysis, respectively. Reprint requests should be sent to the senior author, Department of Psychology, Douglass College, Rutgers University, New Brunswick, N.J. 08903. narrower area of uncertainty, but points of subjective equality did not differentiate the groups. Also, the number of low-anxious reversals increased in the second task to a level similar to that of high-anxious Ss. Absolute and difference thresholds were not correlated, and response latencies were comparable across groups and tasks. Results were discussed in terms of predictions derived from Hull's multiplicative drive theory (Brown, 1961).

The role of motivational variables in perceptual behavior has generally been neglected both in theory and research. Although Brown (1961) attempted to extend Hull's postulates to predict psychophysical relations for simple stimulus events, his data did not permit clear statements as to whether observed differences were due to changes in performance or in associative factors. 


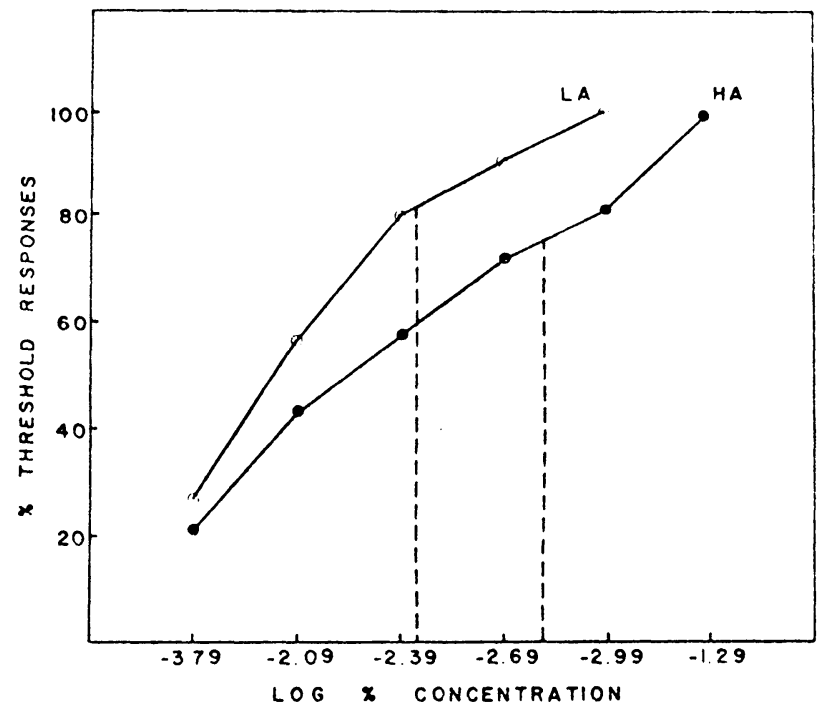

Fig. 1. Differences in psychophysical functions of n-octanol for high- and low-anxious Ss. Dotted lines indicate RLs. Although the value corresponding to $\mathbf{5 0 \%}$ detection generally defines $R L$, procedures requiring two or more "yes" responses usually result in detection approximating $75 \%$, as presently seen.

Recently, Stephens (1970) found that Ss with high test-defined anxiety yielded larger loudness function exponents than low-anxious Ss. Since anxiety has also been related to $S$ attitude (Ruebush, 1960) and performance on tasks varying in complexity (Spence, 1956; Wu \& Lipsitt, 1965), it was selected as the motivational variable for the present study of olfactory threshold determination.

Level of anxiety was measured by extreme performance on the Taylor Manifest Anxiety Scale (MAS; Taylor, 1953), shown to identify Ss with functionally different drive levels whose behaviors in learning tasks concur with predictions generated by Hull's basic assumptions (Spence, 1956). Also, such scores correlate substantially with clinical criteria (Taylor, 1956) and with physiological emotional indices (Spence, 1958).

\section{METHOD \\ Subjects}

Forty female nonpsychology majors were selected from a pretested population of 160 college sophomores on the basis of extreme quartiles of the MAS. High-anxious scores ranged from 31 to $44(\overline{\mathrm{X}}=36.4, \mathrm{SE}=0.8)$; low-anxious scores ranged from 7 to $12(\overline{\mathrm{X}}=9.0, \mathrm{SE}=0.3)$. Six high- and four low-anxious Ss giving positive responses to the odorless control stimulus were discarded from the sample, leaving 14 high- and 16 low-anxious Ss.

\section{Experimenters}

Two females, an undergraduate and a $\mathrm{PhD}$, were Es. Both were naive with respect to MAS scores.

\section{Materials}

$\mathrm{N}$-octanol, supplied by Matheson, was the odorant and odorless-grade diethyl phthalate, supplied by Kay-Fries Chemicals, was the control stimulus and the diluent. A geometric $\left(\log _{2}\right)$ dilution series over 17 concentrations, ranging from $100 \%$ to $0.001 \%$, was prepared in 1-cc quantities and maintained in $10 \times 75 \mathrm{~mm}$ test tubes sealed with foil-wrapped corks. The cotton tip of a wooden swab anchored to the cork remained partially suspended in the odorant when the cork was in place.

The test chamber was sound- and vibration-proof, with an ambient temperature of $72^{\circ} \mathrm{F}$ and an independent ventilation system. A shoulder-high screen spanning the width of a small table separated $\mathrm{S}$ and $\mathrm{E}$.

\section{Procedure}

Absolute (RL) and difference (DL) thresholds of all Ss were determined in a double-blind procedure. Five-second trials were initiated every $20 \mathrm{sec}(\mathrm{RL})$ or every $30 \mathrm{sec}$ (DL) when the E placed the saturated swab about $5 \mathrm{~mm}$ beneath the S's nose. Ss were asked to breathe as naturally as possible (maximum of two breaths) during the stimulation period and to await stimulus removal before responding. Two trial series were presented for each threshold task, with interseries intervals of $60 \mathrm{sec}$.

\section{Absolute Threshold Task}

To minimize sensitivity loss as a function of repeated exposure to intense suprathreshold concentrations, all RLs were determined first. Each $S$ was asked to indicate whether or not the swab held beneath her nose had an odor on it. A practice trial with the odorless diluent, following instructions, familiarized Ss with the temporal aspects of the procedure and permitted monitoring of the breathing technique. It also served as a control stimulus, permitting discontinuation of testing of Ss with strong initial false alarm or positive response tendencies.

Each of the two trial series was begun with the weakest concentration, followed by increasingly stronger odorants on succeeding trials, until positive responses with respect to odor presence had been made on two consecutive trials (Engen, 1963). The geometric mean of the weaker of the two consecutive concentrations eliciting response in each trial series defined $R L$ for a given $S$.

\section{Difference Threshold Task}

Difference thresholds were obtained by a modified method of limits (Rovee, 1969), using a three-category procedure because of its particular susceptibility to $\mathrm{S}$ attitudes and response set. Each S was to sniff the standard stimulus (12.5\% n-octanol) three times rapidly on signal, then inspire naturally while a comparison odorant was held beneath her nose for $5 \mathrm{sec}$. Upon removal of the latter, the $S$ reported whether the odor on it was more intense, equally intense, or less intense than the standard. The range of concentrations for a given $\mathrm{S}$ extended from $100 \%$ to the weakest concentration that had evoked a positive response from her during the RL task.

Each $S$ received one ascending and one descending trial series, with order counterbalanced with anxiety level. Ascending series began with the weakest concentration appropriate for a given $S$ and terminated with either two consecutive "more intense" responses or after the $100 \%$ concentration, whichever occurred first. Descending series began with the $100 \%$ concentration and ended with the second consecutive "less intense" response. In all instances, this was accomplished within the concentration range available to a given $\mathrm{S}$. The most central of the two consecutive concentrations perceived as different from the standard on each trial series marked the upper and lower limen for that series; the two-series geometric means defined the upper and lower limen for a given S. The distance between the latter was that S's area of uncertainty, half of which was the DL. The concentration corresponding to the geometric mean of the upper and lower limen was the point of subjective equality (PSE).

\section{RESULTS}

The mean (geometric) RL of high-anxious Ss significantly exceeded that of low-anxious $\mathrm{Ss}(\mathrm{t}=181.6$, $\mathrm{df}=28, \mathrm{p}<.001)$. Figure 1 shows the psychophysical 
Table 1

Response Summary for High- $(N=14)$ and Low- $(N=16)$ Anxious Ss

\begin{tabular}{|c|c|c|c|c|c|}
\hline \multirow[b]{2}{*}{ Task } & \multirow[b]{2}{*}{ Measures } & \multicolumn{2}{|c|}{ High-Anxious } & \multicolumn{2}{|c|}{ Low-Anxious } \\
\hline & & Mean & SE & Mean & $\mathrm{SE}$ \\
\hline RI & $\begin{array}{l}\text { Concentration (Percent) } \\
\text { Latency (Seconds) } \\
\text { Reversals (Total) }\end{array}$ & $\begin{array}{l}0.06 \\
3.07 \\
1.71\end{array}$ & $\begin{array}{l}0.01 \\
0.02 \\
0.45\end{array}$ & $\begin{array}{l}0.03 \\
3.41 \\
0.44\end{array}$ & $\begin{array}{l}0.01 \\
0.32 \\
0.22\end{array}$ \\
\hline DL & $\begin{array}{l}\text { Area of Uncertainty (Percent) } \\
\text { PSE (Percent Standard) } \\
\text { Latency (Seconds) } \\
\text { Reversals (Total) }\end{array}$ & $\begin{array}{r}26.59 \\
18.40 \\
3.08 \\
2.79 \\
\end{array}$ & $\begin{array}{l}6.32 \\
4.47 \\
0.24 \\
0.64\end{array}$ & $\begin{array}{r}35.36 \\
21.27 \\
3.24 \\
2.71 \\
\end{array}$ & $\begin{array}{l}2.34 \\
2.83 \\
0.41 \\
0.56\end{array}$ \\
\hline
\end{tabular}

functions for RL generated by the two groups. Although mean PSE did not differentiate the groups, high-anxious Ss responded within a narrower range of concentrations than did low-anxious Ss $(\mathrm{t}=26.3, \mathrm{df}=28, \mathrm{p}<.01)$. Ss responded with equal rapidity within a mean range of 3.0-3.5 sec, irrespective of anxiety group or task. Response measures for high- and low-anxious Ss in both tasks are summarized in Table 1.

The response vacillation of Ss prior to final determination of threshold was measured by the number of reversals, or single intrusions of alternative responses, in the same category. Both the absolute number of reversals in each threshold task (totals of two series) and the percent of Ss contributing reversals are shown in Table 2. High-anxious Ss produced almost $3 \frac{1 / 2}{2}$ times more than low-anxious Ss on the RL task $(t=2.65$, $\mathrm{df}=28, \quad \mathrm{p}<.02)$, and a larger percentage of high-anxious Ss were responsible for the reversals $(\mathrm{t}=2.55, \mathrm{p}<.05)$. Although the absolute number of reversals increased for both groups during the DL task $(\mathrm{t}=2.83, \mathrm{df}=29, \mathrm{p}<.01)$, those of low-anxious Ss more than quintupled $(\mathrm{t}=2.80, \mathrm{df}=15, \mathrm{p}<.02)$. Total reversals did not differentiate anxiety groups in the DL task. These data correspond to the postexperimental report of approximately $60 \%$ of the Ss questioned, that the second task seemed more difficult.

The correlation between RL and DL for all Ss was negligible $(r=0.12)$, as were correlations between anxiety score and both $\mathrm{RL}(\mathrm{r}=0.21)$ and $\mathrm{DL}(\mathrm{r}=0.16)$.

\section{DISCUSSION}

The displacement of the psychophysical function for high-anxious Ss to the right of the low-anxious function and the concomitant rise in high-anxious $\mathrm{RL}$ is consistent with the hypothetical threshold function predicted by multiplicative drive theory for motivational effects on associative strength and with functions obtained under instructions to "pay attention" and "try harder" (Brown, 1961). Had motivation affected drive

Table 2

Reversals for High- and Low-Anxious Ss

\begin{tabular}{clcc}
\hline Task & Measures & High & Low \\
\hline \multirow{2}{*}{ RL } & Total Reversals & 24 & 7 \\
& Percent-Ss & 64 & 25 \\
DL & Total Reversals & 39 & 38 \\
& Percent-Ss & 64 & 56 \\
\hline
\end{tabular}

factors, the slope of the predicted function would have been steeper across middle intensities but the RL per se would not have changed. However, the steeper response slope seen for high-anxious Ss in the DL task about a common PSE would be attributable to effects on drive factors and inconsistent with the associative interpretation of absolute threshold performance. Insofar as there was no correlation between $\mathrm{RL}$ and $\mathrm{DL}$, it is not clear that the same factors operated in both tasks. The negligible correlation could be a function of the three-category DL procedure, real differences in personality variables, differential learning within tasks, or some combination of these.

The high number of intrusions by high-anxious Ss in the RL task is reminiscent of Osgood's (1953) early comment that Ss trying too hard to cooperate are more likely to produce response errors in serial threshold tasks. Similar to the finding of Stephens (1970) that high-anxious Ss tended to assign extreme values to different stimulus levels in loudness magnitude estimation, present high-anxious Ss made more extreme response reversals in nonadjacent categories than did low-anxious Ss (i.e., used the middle category less often in consecutive responding). And, similar to the Stephens' finding, high-anxious Ss over suprathreshold intensities appear to be more discriminating than low-anxious Ss.

It is somewhat surprising that so nebulous a variable as anxiety would produce results consistent with those obtained using another psychophysical procedure, another modality, and an alternative test for defining anxiety. The inconsistencies in prediction of DL performance from RL task performance by multiplicative drive theory may stem from factors not affecting the second task, including a potential warm-up effect.

\section{REFERENCES}

Brown, J. S. The motivation of behavior. New York: McGraw-Hill, 1961.

Engen, T. Cross-adaptation to the aliphatic alcohols. American Journal of Psychology, 1963, 76, 96-102.

Osgood, C. E. Method and theory in experimental psychology. New York: Oxford University Press, 1953.

Rovee, C. K. Psychophysical scaling of olfactory response to the aliphatic alcohols in human neonates. Journal of Experimental Child Psychology, 1969, 7, 245-25 4.

Ruebush, B. K. Interfering and facilitating effects of test anxiety. Journal of Abnormal \& Social Psychology, 1960, 60, 205-212.

Spence, K. W. Behavior theory and conditioning. New Haven: Yale University Press, 1956.

Spence, K. W. A theory of emotionally based drive (D) and its relation to performance in simple learning situations. American Psychologist, 1958, 13, 131-141.

Stephens, S. D. Personality and the slope of the loudness function. Quarterly Journal of Experimental Psychology, 1970, 22, 9-13.

Taylor, J. A. A personality scale of manifest anxiety. Journal of Abnormal \& Social Psychology, 1953, 48, 285-290.

Taylor, J. A. Drive theory and manifest anxiety. Psychological Bulletin, 1956, 53, 303-319.

Wu, J. C.-Y., \& Lipsitt, L. P. Effects of anxiety and stress on verbal mediation in children. Psychonomic Science, 1965, 2 , 13-14.

(Received for publication May 10, 1973.) 